NBER WORKING PAPER SERIES

HOW JAPAN AND THE US CAN REDUCE THE STRESS OF AGING

Claudia Goldin

Working Paper 22445

http://www.nber.org/papers/w22445

\author{
NATIONAL BUREAU OF ECONOMIC RESEARCH \\ 1050 Massachusetts Avenue \\ Cambridge, MA 02138 \\ July 2016
}

Written for the ESRI-NBER International Conference, 2016, "Aging in Japan: The Impact of the Retirement of Japan's Baby Boomers." I thank Yuezhou (Celena) Huo who created and computed the simulations and without whom this paper could not have been written. I also thank Susumu Kuwahara of ESRI for providing data on Japan. The views expressed herein are those of the author and do not necessarily reflect the views of the National Bureau of Economic Research.

NBER working papers are circulated for discussion and comment purposes. They have not been peer-reviewed or been subject to the review by the NBER Board of Directors that accompanies official NBER publications.

(C) 2016 by Claudia Goldin. All rights reserved. Short sections of text, not to exceed two paragraphs, may be quoted without explicit permission provided that full credit, including () notice, is given to the source. 
How Japan and the US Can Reduce the Stress of Aging

Claudia Goldin

NBER Working Paper No. 22445

July 2016

JEL No. I10,J11,J14,J26

\begin{abstract}
The Japanese are becoming older. Americans are also becoming older. Demographic stress in Japan, measured by the dependency ratio (DR), is currently about 0.64 . In the immediate preWWII era it was even higher because Japan's total fertility rate (TFR) was in the 4 to 5 range. As the TFR began to decline in the post-WWII era, the DR fell and hit a nadir of 0.44 in 1990. But further declining fertility and rising life expectancy caused the DR to shoot up after 1995.

In this short note I simulate the DR under various conditions and make comparisons with the US. Japan has experienced a large increase in its DR because its fertility rate is low, its people are long lived and it has little immigration. Fertility is the largest of the contributors in Japan. If there are no demographic changes in Japan, the DR will be 0.88 by 2050 . I also assess the role of the "baby boom" of the late 1940s and show that it was compensatory, unlike that in the US. The good news is that healthier older longer-lived people will continue to be employed for many more years than previously and that is one way to reduce demographic stress.

\author{
Claudia Goldin \\ Department of Economics \\ Harvard University \\ Cambridge, MA 02138 \\ and NBER \\ cgoldin@harvard.edu
}


The Japanese are becoming older. Americans are also becoming older. But an older population is not necessarily a bad thing. In fact, the poorest, most underdeveloped nations are the youngest. What, then, is the concern about aging? ${ }^{1}$

A primary worry about an aging population is the growth of the dependency ratiooften measured as the ratio of the young ( 0 to 14 years) plus the old (65 years plus) relative to all others (15 to 64 years). We can also call this ratio "demographic stress." The ratio was constructed to be a proxy for the number of economically inactive individuals supported financially and often cared for by each in the economically active group. The concern with aging, therefore, is that the number of non-economically active individuals is growing relative to the economically active, and therefore the non-economically active will have a decreased standard of living and fewer to care for them.

But those dire consequences may not occur in an open economy with sufficient savings and "guest workers" (or perhaps robots). Sufficient savings in an open economy will ensure resources in older age and "guest workers" (or robots) will close the caregiving gap. ${ }^{2}$ The concern with an aging society seems much deeper, however, and often concerns the preservation of a national society and economy. I will, however, put these deeper concerns and macroeconomic issues aside and confine my comments to the demographic and labor force aspects of the issue.

The questions I pose are: What are the demographic, societal and labor market forces that have led to the aging of the Japanese and American populations, what are the economic consequences and what does the future hold?

Populations evolve because of three factors: fertility, mortality and net immigration. The Japanese have been extraordinarily good at expanding the longevity of their population. They are the best in the world, especially for women. But they have not been very good at increasing fertility, and immigration has been very low until recently.

\footnotetext{
${ }^{1}$ For a recent paper on the benefits of below replacement fertility with increased longevity see Lee, Mason et al. (2014).

2 On aging and saving in an open economy, see Elmendorf and Sheiner (2000).
} 
Whereas mortality changes are generally secular and continuous, fertility and immigration changes are often sporadic and discontinuous. One of the themes of this meeting is the "Japanese baby boom," a sporadic increase in Japanese fertility from 1947 to 1949 resulting in a group that today is between 67 and 69 years old.

But how much of the Japanese problem with aging is due to increases in longevity and how much is due to declining fertility? What role is played by the "baby boom" of the late 1940s, about which this conference is concerned, and what is due to limits on immigration to Japan? ${ }^{3}$

I will pose similar questions for the US, which had a considerably larger post-WWII baby boom than did Japan, in the analysis below extending from 1947 to $1964 .{ }^{4}$ Whereas the Japanese "baby boom" was primarily compensatory, making up for the decline in births during the war, that for the US extended well beyond the period that would have made up for the deficit of births to particular cohorts of women. Another difference is that the US has a much larger flow of both legal immigrants and the undocumented.

The answers from the simulations I construct are that increased longevity is important in Japan but is not the most important factor. The post-WWII baby boom in Japan is a current factor but not a major one in causing demographic and economic stress. The major factor for the long run is the "baby famine" that began just after 1975.

I will then ask why the fertility rate is so low in Japan and provide answers that are similar to those provided by others in a large literature. In particular, I discuss Japan's position in the U-shaped function of economic development, fertility and women's employment. I end with a discussion of how older individuals, particularly women, have adjusted their lifecycle labor force participation to healthier, longer lives and to jobs that are not as physically demanding as they once were and are often socially and intellectually

\footnotetext{
${ }^{3}$ Hock and Weil (2012) discuss the complicated relationship between fertility and the dependency ratio through consumption.

4 The US baby boom is generally considered to have extended from 1946 to 1964.
} 
rewarding. These labor force adjustments may be the answer to the demographic and economic stress of aging in a low fertility environment.

\section{Demographic Change in Japan and the US}

The Japanese birth rate (TFR) is currently 1.4 (see Table 1) and life expectancy at birth is 83.4 years ( 80.2 for men and 86.6 for women)..$^{5}$ Although there was an increase in immigration in the 2000s, it is still relatively low and accounts for just 1.7 percent of the 2010 population. ${ }^{6}$ The median age of the Japanese population in 2010 was 44 years old.

In comparison, the US birth rate (TFR) is currently 1.9 and life expectancy at birth is 78.7 years (76.4 for men and 81.2 for women). Immigration (including the illegal population) is 13 percent of the total 2010 population. $^{7}$ The median age of the US population in 2010 was 34 years old.

The Japanese edge on the US in terms of life expectancy can be seen another way. In 2010 the ratio of American to Japanese 50-year olds was 3.0 but the ratio at age 80 was just 1.3. In both countries, a post-WWII Baby Boom occurred that is currently in their late sixties. In Japan the post-WWII Baby Boom lasted from 1947 to 1949 and in the US from 1946 to around 1964, although our simulations will begin with 1947.

The "demographic stress" in both Japan and the US can be seen in Figure 1, which gives the ratio of the two tails of the distribution to the middle. In this case, the young are defined as 0 to 14 years and the old are defined as 65 years and older; the middle is everyone else, 15 to 64 years old.

\footnotetext{
${ }^{5}$ For life expectancy, see https://data.oecd.org/healthstat/life-expectancy-at-birth.htm\#indicatorchart, which gives the data for 2013 (used as well for the US).

${ }^{6}$ From 2000 to 2009 Japanese immigration increased from $1.686 \mathrm{M}$ to $2.186 \mathrm{M}$. The population in 2010 was $128.06 \mathrm{M}$. The increased immigration of $1.132 \mathrm{M}$ from 2000 to 2009 was 44 percent of the total change in population.

7 The US foreign-born population (including an estimate of illegals) increased from $31.11 \mathrm{M}$ to $39.96 \mathrm{M}$ from 2000 to 2009 and the total population in 2010 was $308.75 \mathrm{M}$. See http://www.migrationpolicy.org/programs/data-hub/us-immigration-trends\#history
} 


\section{Demographic Stress in Japan}

The actual amount of demographic stress in Japan, as measured by the dependency ratio (DR) and given by the red line in Figure 1, is currently about 0.64 . This means that, given the DR measure employed here, there are 64 young and old persons per 100 economically and physically active persons. In the immediate pre-WWII era it was around 0.70 largely because Japan's TFR had been in the 4.1 to 5.1 range from 1925 to $1940 .{ }^{8}$ As the TFR began to decline in the post-WWII era, the DR fell and hit a nadir of 0.44 in 1990. With declining fertility and rising life expectancy the DR then began to shoot up around 1995 and it is currently around 0.64 .

But what would the DR look like if current TFR and mortality levels are sustained into the distant future and if immigration policy does not change? What would the DR be if hypothetical, but reasonable levels of TFR and mortality were assumed? And what would the DR be had there not been a post-WWII baby boom? The answers are provided in Figure 2.

In Figure 2, Part A the TFR by age group and death rates by age are kept at their 1975 levels and the DR is computed to 2014. Figure 2, Part B extends the TFR analysis to 2054. A justification for using the 1975 TFR in Parts A and B of Figure 2 is that the aggregate level at that time in Japan was 1.91, which is about the level in the US and several northern European nations today. Another reason is that 1975 was around the start of the precipitous decline in TFR in Japan to its current level of around 1.4. The mortality counterfactual is more controversial and is to hold death rates by age constant at their 1975 level. The mortality counterfactual is far more difficult to justify since few would want to decrease the DR by reducing life expectancy. Therefore the long-run analysis is computed only using the fertility counterfactual.

The counterfactuals in Figure 2, Part A demonstrate that increasing fertility (given

${ }^{8}$ Data provided to me from the National Institute of Population and Social Security Research give TFR levels as 5.1 (1925), 4.7 (1930), and 4.1 (1940). No data prior to 1925 were provided. 
by the purple line) would actually raise the DR to 2014, from around 0.624 to $0.67 .{ }^{9}$

Decreasing life expectancy, the mortality counterfactual, would lower the DR to 0.52 (given by the green line).

Although increasing fertility would elevate the DR over the short run, what would the DR be in the long run as the population adjusted to the higher counterfactual fertility rate? The answer is given in Figure 2, Part B.

The actual DR (simulated with real TFR and actual mortality rates), given by the (dotted) red line, holds all demographic factors after 2014 constant at their 2014 levels. By 2054 the projected long-run DR would be around $0.88 .{ }^{10}$ If, instead, the fertility rate were kept at 1.91 (recall, that was the rate in 1975 Japan), the DR would level out at 0.73 (as shown by the purple line). The purple line in Figure 2 Part B is identical to the purple line in Part A up to 2014. Even though the adjustment to the counterfactual fertility rate to 2014 was to increase the DR above the actual level, the DR drops in the long run and the crossover point is around 2030. Thus increasing fertility to its pre-decline level would reduce the long-run DR by 15 percentage points. ${ }^{11}$

Figure 2, Part C gives the long-run adjustment to the mortality rate existing in Japan in 1996 (rather than the rate in 1975 as in Figure 2, Part A). ${ }^{12}$ The reduction in life expectation decreases the DR from 0.62 to 0.60 , a trivial amount. But this is not a counterfactual worth considering.

Perhaps the most interesting of the counterfactuals, especially given the title of the conference, is that in Figure 2, Part D. Note that the red line in Part D is the (simulated version of the) actual DR and is the same as in Figure 1. The post-WWII baby boom is assessed in several ways. One constraint is that the data on fertility rates by age exist only

\footnotetext{
9 The actual DR in 2014 was 0.64 . The simulated DR in that year is slightly lower.

10 Although the simulation in Figure 2, Part B is run to 2054, the population is about in steady state then and the DR remains at around 0.86 for another 75 years.

11 Note that the change in the DR is expressed in percentage points because it is the change in the fraction of the "economically inactive" population to the "economically active" population. 12 I use 1996 rather than 1975 because rates in Japan in 1996 are approximately what they are in the US today and it does not make sense to apply life expectancy rates that are lower.
} 
for 1940, 1947 and 1950 and therefore no fertility estimates by age exist (or have been made accessible) for the WWII period in Japan.

We can begin with a counterfactual (given as a red dotted line) that smoothes the TFR from 1940 to 1947 and again from 1947 to 1950. By smoothing the TFR from 1940 to 1947 the role of WWII in first reducing the birth rate is ignored (because no estimates have been provided on birth rates in Japan during WWII). Therefore the counterfactual vastly overshoots the actual birth rates in the WWII period. Not only does it do away with the baby boom of the late 1940s, it also gets rid of WWII's impact on fertility, which does not seem reasonable. It can be safely ignored.

The green line in Figure 2, Part D provides the most reasonable counterfactual. This counterfactual smoothes the TFR from 1940 to 1950 and thus allows for the possibility that the post-WWII baby boom was compensatory, in the sense that it made up for the births individual women could not have had during the war. The counterfactual involves no decrease in TFR during the war but also contains no increase in the TFR after the war. After 1950 the counterfactual uses the actual values.

The baby boom counterfactual produces a DR series that is almost identical to the solid red line, giving the simulated values of the actual DR. The fact that these lines are almost identical shows that the post-WWII baby boom was, in fact, nearly compensatory and not a major break with the past, as was the case in the US. I turn now to that case.

\section{Demographic Stress in the US}

To provide reasonable comparisons between the US and Japan, Figure 3 gives a counterfactual that makes fertility and immigration in the US more similar to its rates in Japan for the post-1975 period and then simulates the DR out to 2120. In this fertility and immigration counterfactual, immigration is ended in 1940 and TFR is set at the Japanese level from 1975 to 2014 and then at the current level in Japan after 2014 to 2120.

The DR initially declines after 1975 because of the lower TFR in the counterfactual than in actuality in the US. But after 2030 the DR increases by around 10 percentage points 
as the lower fertility levels impact the age structure of the population. That counterfactual assumes zero immigration to be more consistent with the Japanese case. Changing US immigration back to its actual level in 2014 would reduce the long-run DR by about 10 percentage points. ${ }^{13}$ Changing mortality levels to those in Japan today (with no immigration) would increase the long-run DR by 6 to 7 percentage points.

The baby boom counterfactual in Figure 3, Part B for the US can be directly compared with that for Japan in Figure 2, Part D. The US counterfactual evens out TFR between 1946 and 1965 by trending between those rates. After 1965 TFR assumes its actual US levels. It is clear that the US baby boom was far more than a compensatory change making up for the lower level of births to cohorts of women in the early 1940s. In addition, the decrease in births during the Great Depression could not have been a factor causing the US baby boom since the women impacted in the 1930s would have been too old to have had compensated for their lower births after 1945. The US baby boom was a major change in fertility, although its causes are still somewhat of a mystery. ${ }^{14}$

\section{Low Fertility in Japan}

The importance of low fertility to demographic and economic stress in Japan is clear. Why is fertility low in Japan? Several reasons have been offered including low marriage rates for all education groups. ${ }^{15}$ Among the more highly educated low marriage and fertility rates have been linked to incongruences that arise when economic growth is rapid but traditions change slowly. ${ }^{16}$ Other research has demonstrated that the provision

\footnotetext{
13 Immigration is given by the absolute number of immigrants and not by the fraction of the population who is immigrant.

${ }_{14}$ Although recent research by Albanesi and Olivetti (2016) argues persuasively that decreased maternal morbidity and mortality produced the baby boom and that other, underlying factors, ended it.

${ }^{15}$ According to Matsuda, Sasaki, Takamura et al. (2015) the proximate reason for the decline in the birth rate in Japan since the 1970s is the low marriage rate. But the low marriage rate is a function of a lack of desire to have children and the authors conclude that there is an inherent simultaneity. 16 See the insightful work of Hwang (2016) on "Gold Misses" in Japan and Korea. She finds convincing evidence that rapid economic change and increased education for women has led to conflict between educated women and their potential in-laws and husbands concerning their household role.
} 
of childcare by firms is an important factor and that women in "regular" employment are more likely to have a birth than those in "irregular" or "fixed term" employment. ${ }^{17}$

Fertility rates vary greatly among OECD nations. The Nordic countries and the US have relatively high fertility rates, just below replacement, whereas nations in the southern part of Europe and Japan have low rates, below 1.4. In a thought-provoking and instructive article, Feyrer, Sacerdote and Stern (2008) describe a lifecycle model of fertility, female labor force participation and household production that nations go through during economic development.

When women have low education levels and there is scant labor market work that can be coordinated with their household duties, or that is culturally acceptable, fertility is high. As clerical and professional employments expand relative to agricultural and manufacturing jobs, and as education levels rise, women's employment increases. But because social norms have not yet changed, women are also still expected to take care of the home and their children because men do little in household production. Fertility, in consequence, falls to low levels as women do a "double shift."

The next phase in the lifecycle of nations is that fathers and husbands begin to take more responsibility in the household. National and firm policies respond. Parental leave and childcare expand through private and public provision. Fertility rates then increase and female labor force participation expands. At the end of the lifecycle of nations, considerably more gender equality in the household and the labor market emerges, and fertility levels rise to around replacement.

Feyrer, Sacerdote and Stern (2008) demonstrate this hypothetical relationship in cross section using data for 1995 and labor force participation rates for 20 to 39 year old women. I have updated their analysis using data for 2014 and I have changed the ages for employment to 25 to 34 years old to avoid confusing a decrease in market work with an

\footnotetext{
17 Sato, Asai, Takamura, et al. (2014) mention that fertility is lower for fixed-term employees because regular employees get various maternal benefits. The authors mention as reasons for their not having another child women's being "irritated" with their childcare and household burdens.
} 
increase in college education. I have also used the employment to population ratio rather than labor force participation because of high rates of unemployment in southern Europe. Finally, I have presented the data in two ways: for all female workers in the relevant age group and for the full-time group (OECD definition of 30 hours or more per week). Figure 4, Parts A and B show the relationship.

Looking first at Figure 4, Part A, Greece, Italy and Spain have the lowest TFR and also the lowest female employment rates. Portugal is a bit of an outlier since its female employment rates are high given its TFR. Japan has low fertility and lower female employment than some of the other nations but not as low as that in much of southern Europe. The Nordic countries (Denmark, Finland, Norway, Sweden) Britain, France, the US and others have TFR in the 1.7 to 2.0 range and generally higher female employment rates. The full relationship appears distinctly like the bottom and upward portions of the Ushaped relationship just discussed. ${ }^{18}$

Because in many nations women work low hours to mesh their employment with household duties, Figure 4, Part B gives the same relationship but uses the OECD full-time employment definition of 30 hours per week and above at the employee's usual job. The relationship looks even more like the bottom and upward portions of a U-shape. The US, which has low levels of part-time work, is now closer to the line and the Netherlands, which has considerable part-time work, is farther away, to give two examples.

Women's employment in Japan greatly increased from 1995 to 2014. In the original Feyrer, Sacerdote and Stern (2008) graph, Japan looked more like Spain both in its fertility and female employment rates. But Japan's female population has been marrying later and women are employed to a greater extent, although many work part-time. The extent of part-time employment in Japan can be inferred by comparing the two parts to Figure 4: the total employment number is 0.72 but the full-time ratio is 0.52 (where full-time is defined as 30 hours and above). Fertility has remained low in Japan during the last two decades as

\footnotetext{
18 Nations with extensive parental leave policies (e.g., Nordic countries; Britain; France) will have higher employment rates than those with less generous policies (e.g., US) because those on leave are counted as employed in most national data.
} 
can be seen from Table 1, although the TFR has increased in recent years. TFR had decreased to a low of 1.26 in 2005, but has recently returned to its 1995 level of 1.422 .

The bottom line is that women's labor force participation and fertility respond to changes in social norms and traditions that enable and encourage men to contribute more, and possibly even equally, to the care of children and the maintenance of the household. What about the labor force adjustments to increased longevity?

\section{Adjustments to Increased Longevity}

What happens to female labor force participation as populations live longer and as jobs become less physically demanding and more rewarding economically, socially and intellectually? The cases of the US and Japan are instructive. In both nations, labor force participation of women in their sixties and even seventies has increased substantially in the last 25 years.

The US and Japan are apparently among the leading nations in the employment of older women as can been seen in Figure 5 Parts A and B, which give labor force data for seven OECD nations. For women 60 to 64 years old (Part A) there has been increasing labor force participation in most OECD nations. The levels in Sweden and the US have been the highest with Japan and Canada not far behind. For women 65 to 69 years old (Part B) the US and Japan have the highest labor force participation rates. ${ }^{19}$ Japan's has actually been fairly level during the past 25 years. Mean usual weekly hours worked, moreover, are fairly high. In 2015 among 60 to 64 year old women in the labor force, the average workweek in Japan was 29.9 hours and for those 65 to 69 years old it was 28.0. In the US hours per week were somewhat higher for 60 to 64 year old women, 33.9 hours, but hours were about the same, at 29.2 hours, for 65 to 69 year old women. ${ }^{20}$

In the US, older men's labor force participation also increased in the recent past, but that trend reversed a much longer one of decreased participation. Furthermore, the

\footnotetext{
19 It should be emphasized that some of the differences around age 65 may be due to mandatory retirement laws or to tax policy together with social insurance programs.

20 The calculation for the US is made for 2014 from March CPS.
} 
increase for older men is less pronounced that the increase for older women. The trends for older men and women in the US during the last 25 years are given in Table 2 and time trends for women by five-year age groups from 1963 to 2014 are shown in Figure 6 (Goldin and Katz 2016).

The labor force participation of women 60 to 64 years old increased from 0.34 to 0.51 from 1987 to 2014 and participation rates for women 65 to 69 nearly doubled from a base of 0.15. The increases, moreover, have been disproportionately for full-time workers. Thus the increase means greater continuity in the working lives of older workers rather than a change in the phasing-in of retirement. These facts mean that the increase in older women's employment is not simply a switch from full-time to part-time jobs as a step in the progression to a later retirement.

Why have women been working longer? I know the most about the US case and will summarize my findings on it (Goldin and Katz 2016). I have already mentioned that the increase has been primarily among full-time workers. The next point is that women in the most recent cohorts that can be observed to their sixties (late 1940s to 1950s), relative to those in previous cohorts (1930s to early 1940s), have been in the labor force to a greater extent throughout their lives. Therefore, the increased participation of women in their older years derives from the greater continuity of employment among women in birth cohorts beginning with those in the late 1940s. The underlying reasons for the greater continuity are several.

In a simple regression context of labor force participation at older ages (say 59 to 63 years old) this means that the best initial correlate of working longer is birth cohort. More recent birth cohorts (late 1940s, early 1950s) of women have larger coefficients on cohort dummies than do more distant cohorts (1930s). But educational advance, in particular the fraction with a college degree, greatly mutes the impact of cohort effects. The fraction of one's earlier life in the labor force is also of great importance and once that is added to the regression the number of children a woman has had does not affect participation in her older years. Employment early on in professional and managerial occupations has an impact on later participation. But inclusion of past labor force history greatly absorbs that 
effect. For those in good health, financial security matters to some degree as does whether the woman's husband is in the job market or is retired.21

\section{Discussion and Conclusion}

The main points of this brief paper are that demographic stress-an increase in the dependency ratio-is apparent in many developed nations. Japan has experienced a larger increase than in most other nations because its fertility rate has been low, its people have experienced an increase in longevity and it has little immigration of the prime-aged. The simulations I have presented indicate that fertility is the biggest of the issues in Japan. The simulations also show that the immediate post-WWII baby boom, a focal point of this conference, was a minor blip in Japan's demographic history, certainly relative to the baby boom in the US.

The baby famine in Japan, ongoing since the early 1980s, has similar causes to that in southern Europe. It is conceivable that eventual changes in norms at home and in traditions in the labor market will serve to increase birth rates from their currently low levels.

The good news is that healthier older people with long lives ahead of them will continue to be employed for many more years than they were previously. Cohorts who have worked in satisfying, less physically taxing, jobs for much of their lives will continue to do so. Women in the US have demonstrated that they prefer to be employed than to retire when they are in good health and their jobs are fulfilling even if they have reasonable financial security.

The bottom line is that to avoid the impact of demographic stress, increasing the labor force participation of the older population is probably the best and most feasible way.

\footnotetext{
${ }^{21}$ Lee, Mason et al. (2014) point out that longer and healthier lifetimes mean a higher female labor force participation rate. Although one would think that women have become healthier, the Health and Retirement Study (for the US) does not show that older women are healthier today than they were 20 years ago.
} 
In terms of the reality, it will mean better, "regular" jobs for women in their early to middle-aged years.

In terms of the simulations, the parameters of the DR would change by extending the economically active population from, say, age 65 to age 70 or even to 75 . If the age range of the economically active population were increased to age 70 the DR in Japan would decrease from around 0.63 to 0.43 and in the US the DR would decrease from 0.51 to 0.39.22 The DR in Japan would be lower than it was in 1975 and that for the US would be lower than it was in 1940. Increasing fertility is another obvious solution in Japan but that would involve major changes to the workplace and society.

22 Note that the ratio is sensitive to this change because it shifts both the numerator and denominator. If the DR were expressed as a fraction of the total population, the change would seem much smaller (e.g., 0.63 to 043 would be 0.39 to 0.30 ). The US has increased the age of receiving full Social Security benefits and such changes would be expected to encourage work at older ages. 


\section{References}

Albanesi, Stefania and Claudia Olivetti. 2016. "Gender Roles and Medical Progress," Journal of Political Economy 124(3): 650-95.

Elmendorf, Douglas W. and Louise M. Sheiner. 2000. "Should America Save for Its Old Age? Fiscal Policy, Population Aging, and National Saving," Journal of Economic Perspectives 14(3): 57-74.

Feyrer, James, Bruce Sacerdote and Ariel Dora Stern. 2008. "Will the Stork Return to Europe and Japan? Understanding Fertility Within Developed Nations," Journal of Economic Perspectives 22(3): 3-22.

Goldin, Claudia and Lawrence F. Katz. 2016. "Women Working Longer: Facts and Some Explanations." Paper presented to the Women Working Longer Conference. NBER, Cambridge MA, May 21-22, 2016.

Hock, Heinrich and David N. Weil. 2012. "On the Dynamics of the Age Structure, Dependency, and Consumption," Journal of Population Economics 25(3): 1019-43.

Hwang, Jisoo. 2016. “Housewife, 'Gold Miss,' and Equal: The Evolution of Educated Women's Role in Asia and the U.S.," Journal of Population Economics 29(2): 529-70.

Lee, Ronald, Andrew Mason et al. 2014. "Is Low Fertility Really a Problem? Population Aging, Dependency, and Consumption," Science 346(6206): 229-34.

Matsuda, Shigeki, Takayuki Sasaki, Shizuka Takamura, et al. 2015. "Analysis of the Relation between Low Fertility and Living Conditions among Never-Married Women: Empirical Evidence from Survey Data." ERSI Discussion Paper Series No.323 (August). Full text in Japanese.

Sato, Hiroki, Yukiko Asai, Shizuka Takamura, et al. 2014. "Analysis of Employment, Childbirth, Childrearing and Living Conditions of Married Women: Empirical Evidence from Survey Data." ESRI Discussion Paper Series No.311. (June). Full text in Japanese. 
Figure 1: Dependency Ratios (DR) for Japan and the US: 1935 to 2014

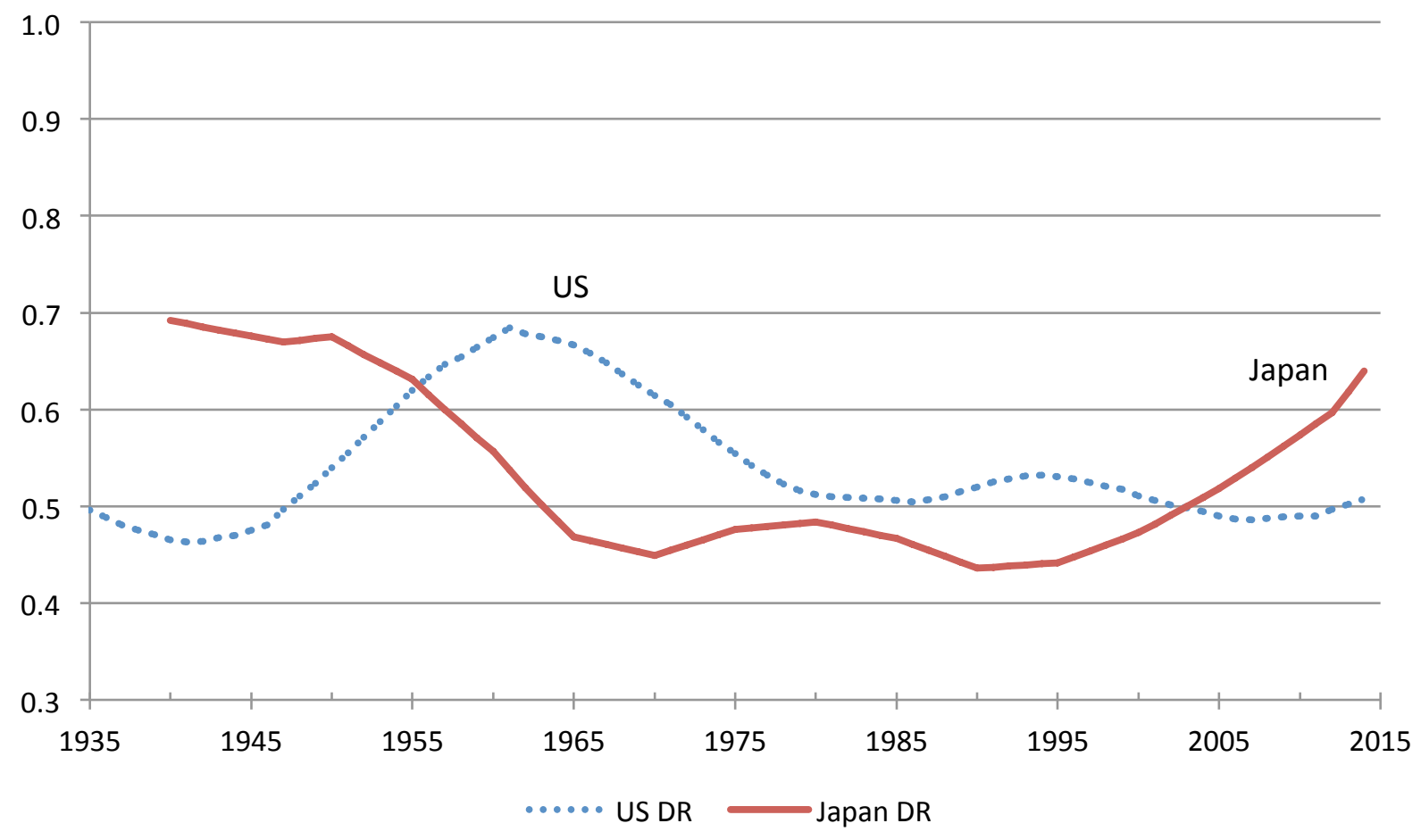

Sources: US: US Census Bureau; Japan: Japanese Ministry of Health, Labour and Welfare (from files pop_female_japanese.csv and pop_male_japanese.csv).

Notes: $\mathrm{DR}=$ dependency ratio $=[(0-14$ years $)+(65+$ years $)] /(15-64$ years $)$. 
Figure 2: The Causes of Demographic Stress, Japan

A. Fertility and Mortality Counterfactuals to 2014, Japan

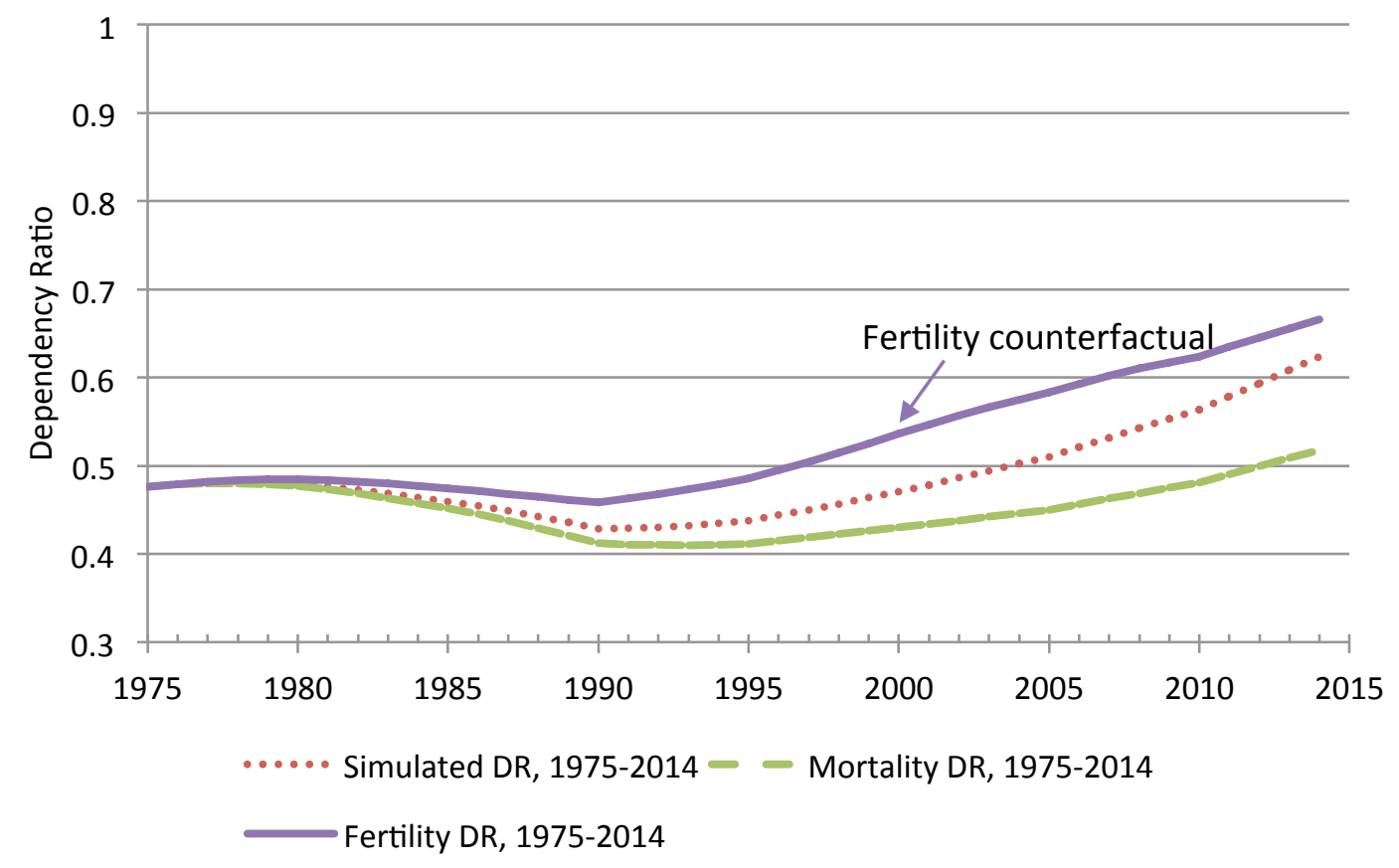

B. Fertility Counterfactual to 2054, Japan

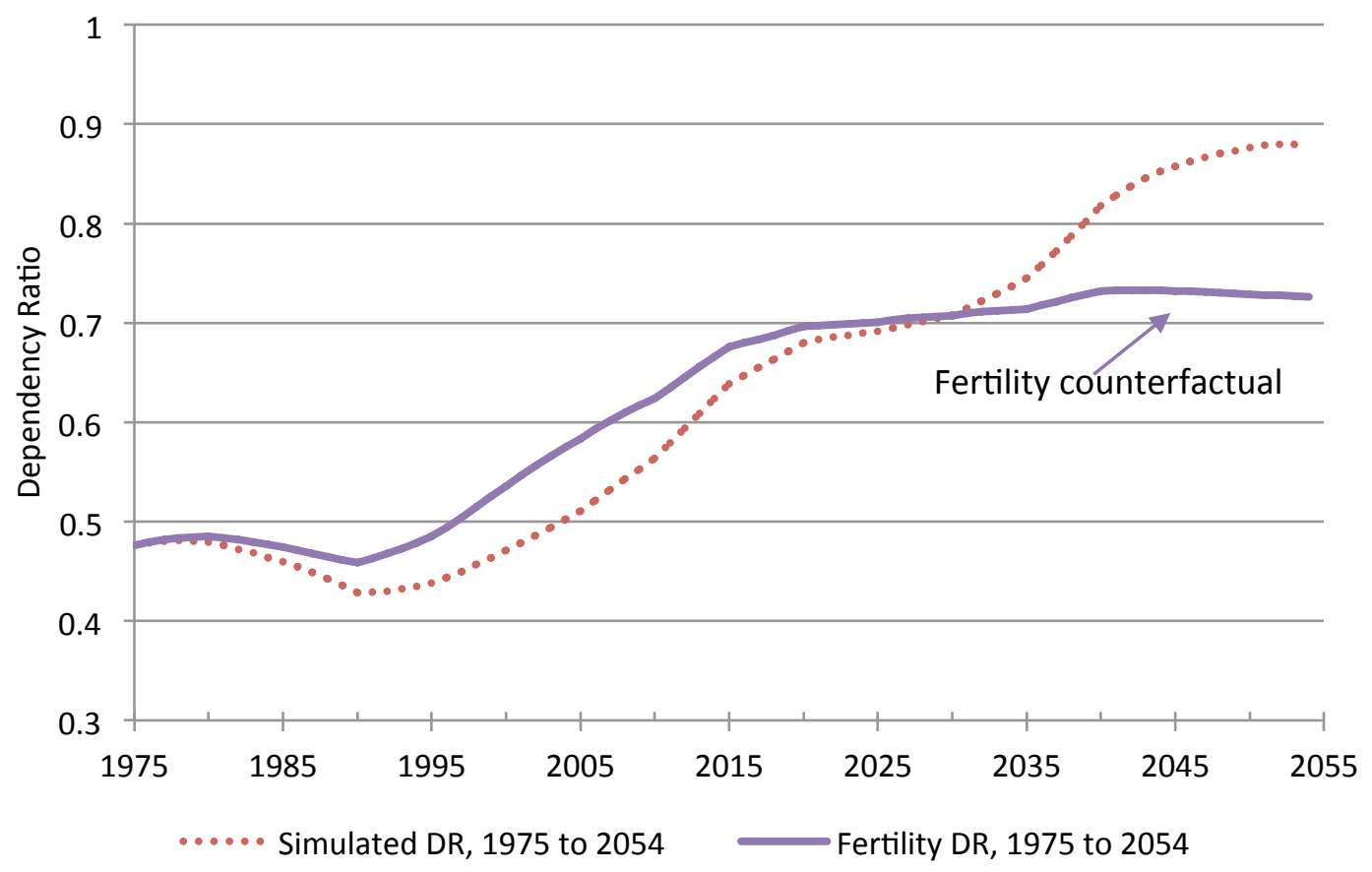


C. Mortality Counterfactual to 2014, Japan

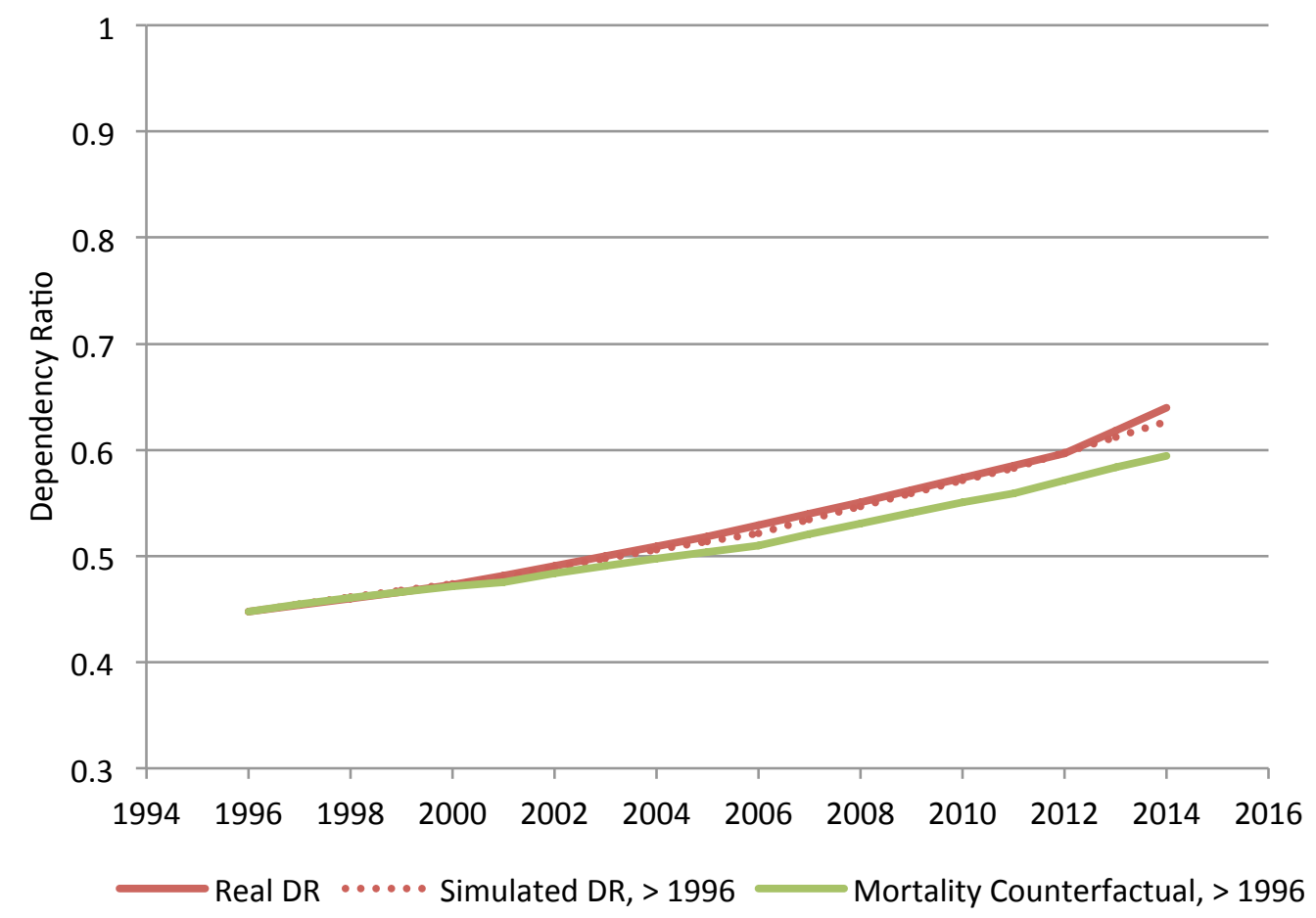

D. Baby Boom Counterfactual, Japan

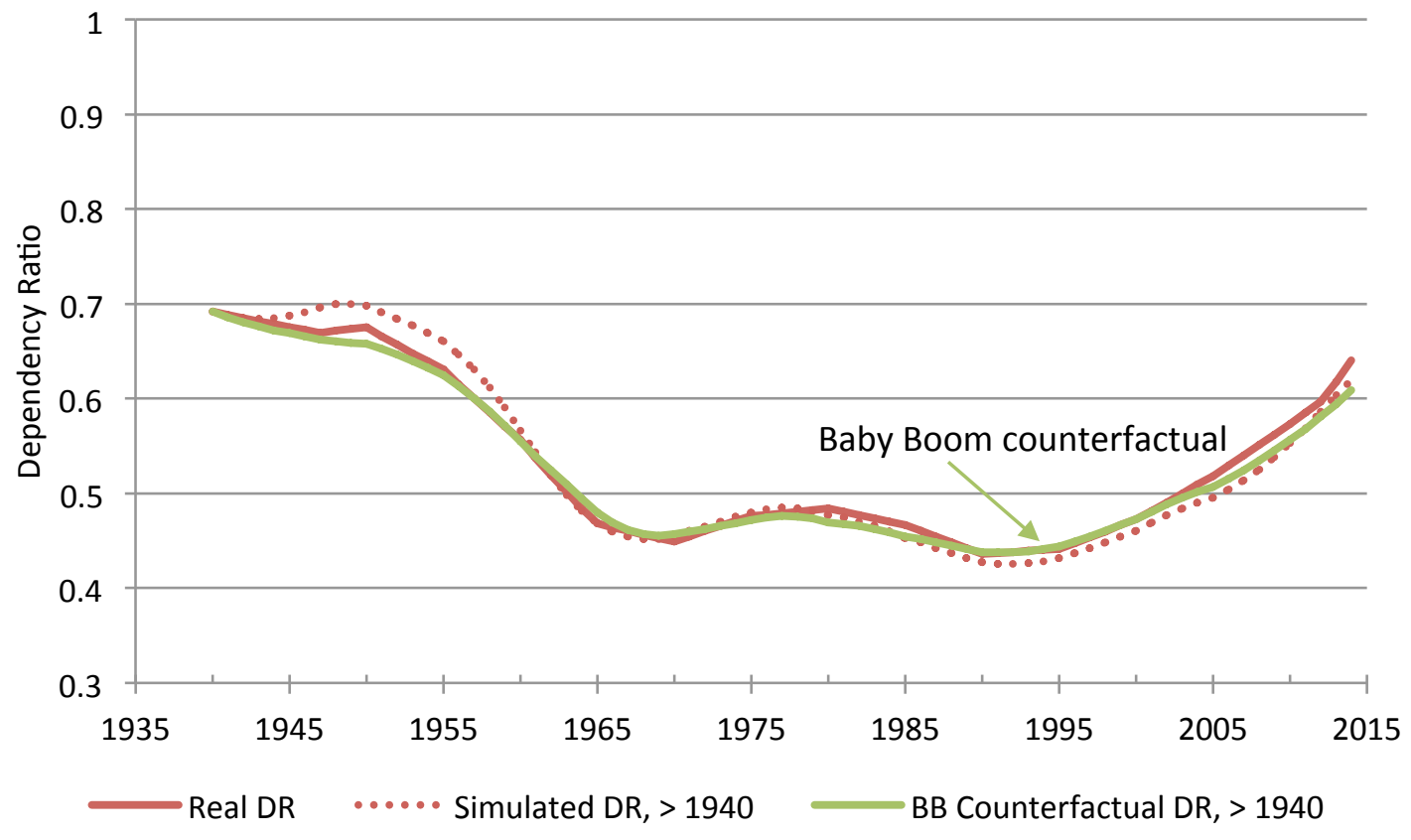


Sources: TFR (total fertility rates) by age and year from Japanese Ministry of Health, Labour and Welfare. Mortality data from Japanese Ministry of Health, Labour and Welfare. File name is: japan_mortality_age_sex.xls .

Notes: The simulated DR (dependency ratio $=[(0-14$ years $)+(65+$ years $)] /(15-64$ years $)$ in Parts A, C and D are almost identical to the actual DR. The simulation uses the TFR (total fertility rates) and mortality rates for each interval for consistency with the counterfactuals.

Parts A and B: The fertility counterfactuals hold the age group (i.e. fertility rate for 15-19, 20-24, etc.) specific fertility rate at the level that had existed in 1975. The TFR in 1975 in Japan was 1.91.

Parts A and C: The mortality counterfactual holds age-group specific mortality rates at their 1975 levels, for Part A, and at their 1996 levels, for Part C.

Part D: The simulated DR assumes the same TFR for each of the years given. This means, however, that the TFR between 1940 and 1947 did not drop, as it must have. Therefore, there is too high a birth rate (and thus too high a DR) for the immediate post-war period. The "baby boom" (BB) counterfactual assumes that there was no post-war baby boom and also that the wartime reduction in TFR also did not exist. TFR is smoothed between 1940 and 1950 and is then at its actual rate. 
Figure 3: The Causes of Demographic Stress, US

A. Fertility Counterfactual 1975 to 2120, US

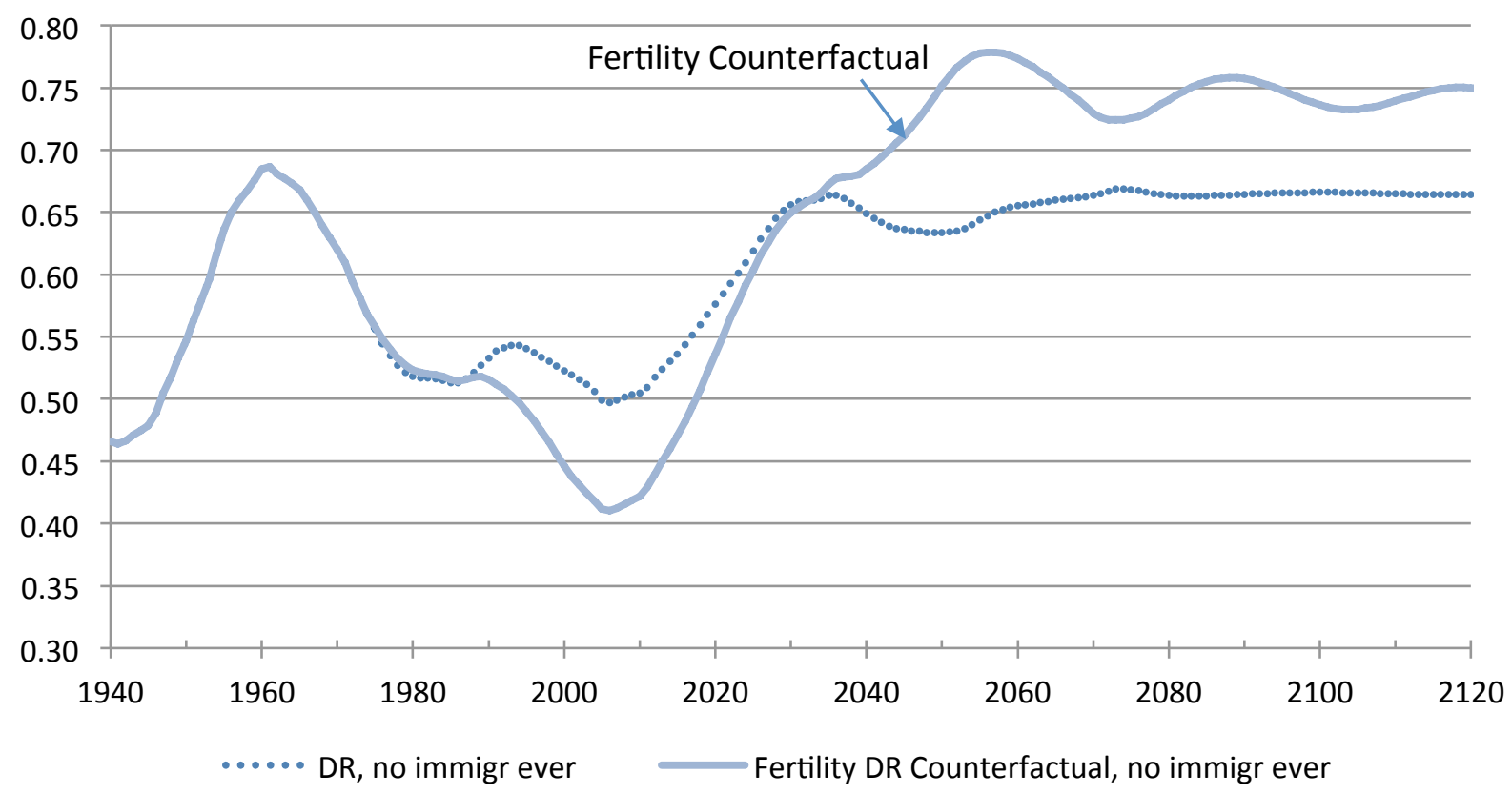

B. Baby Boom Counterfactual, US

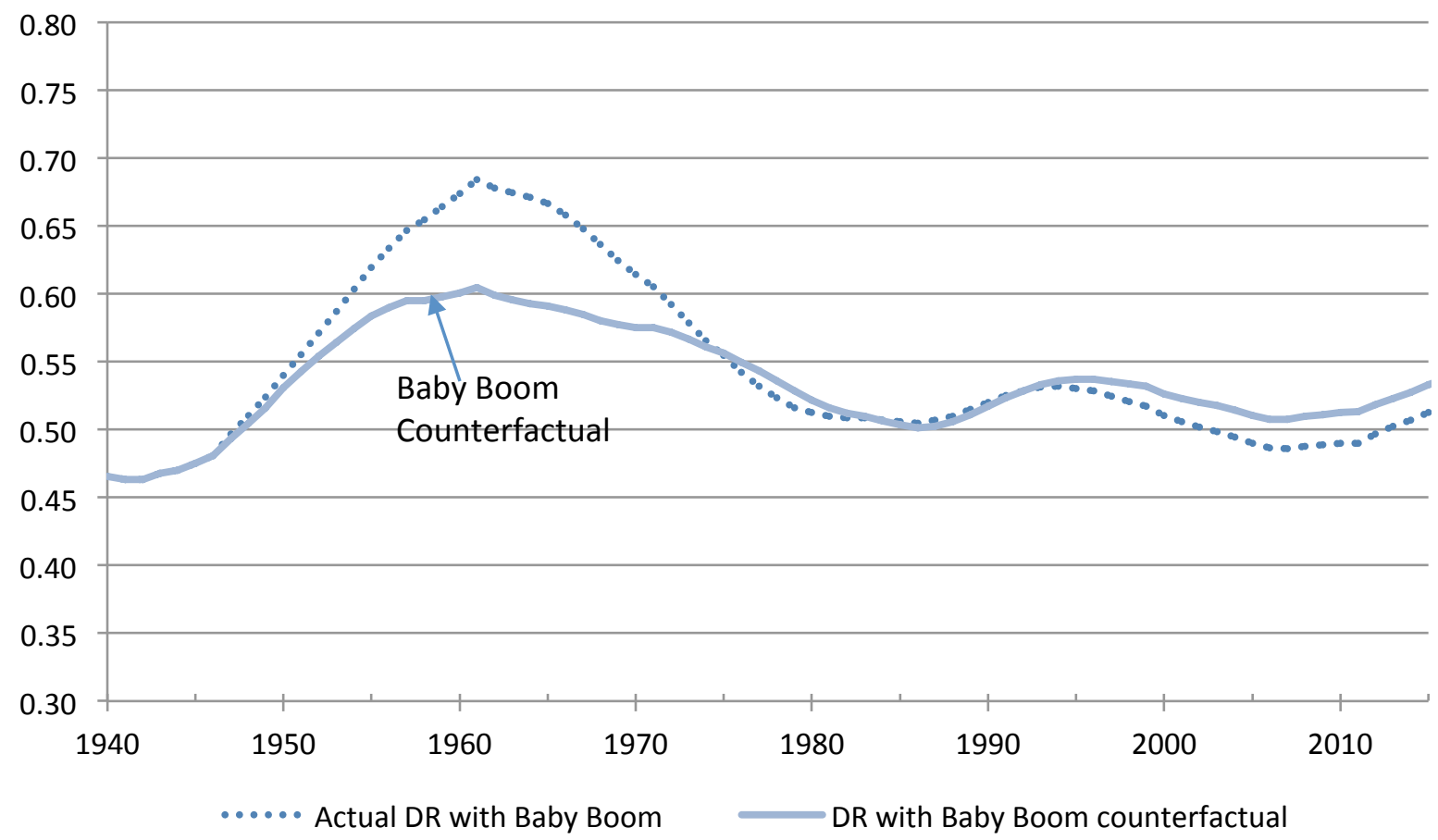


Notes: Part A: The actual DR (with immigration) is the same graph to 2014 as in Figure 1. The projection forward keeps all mortality and fertility parameters the same but reduces immigration flows to zero post-1940. The fertility DR counterfactual (with no immigration) gives the US the Japanese fertility rate after 1975. Part B: Baby Boom counterfactual assumes that TFR was approximately constant from 1946 to 1965 at around 2.9 rather than rising from 2.9 in 1946 to 3.65 in 1960. All other demographic parameters remain at their actual values. 
Figure 4: Total Fertility Rates and Employment to Population for Women: OECD, 2014
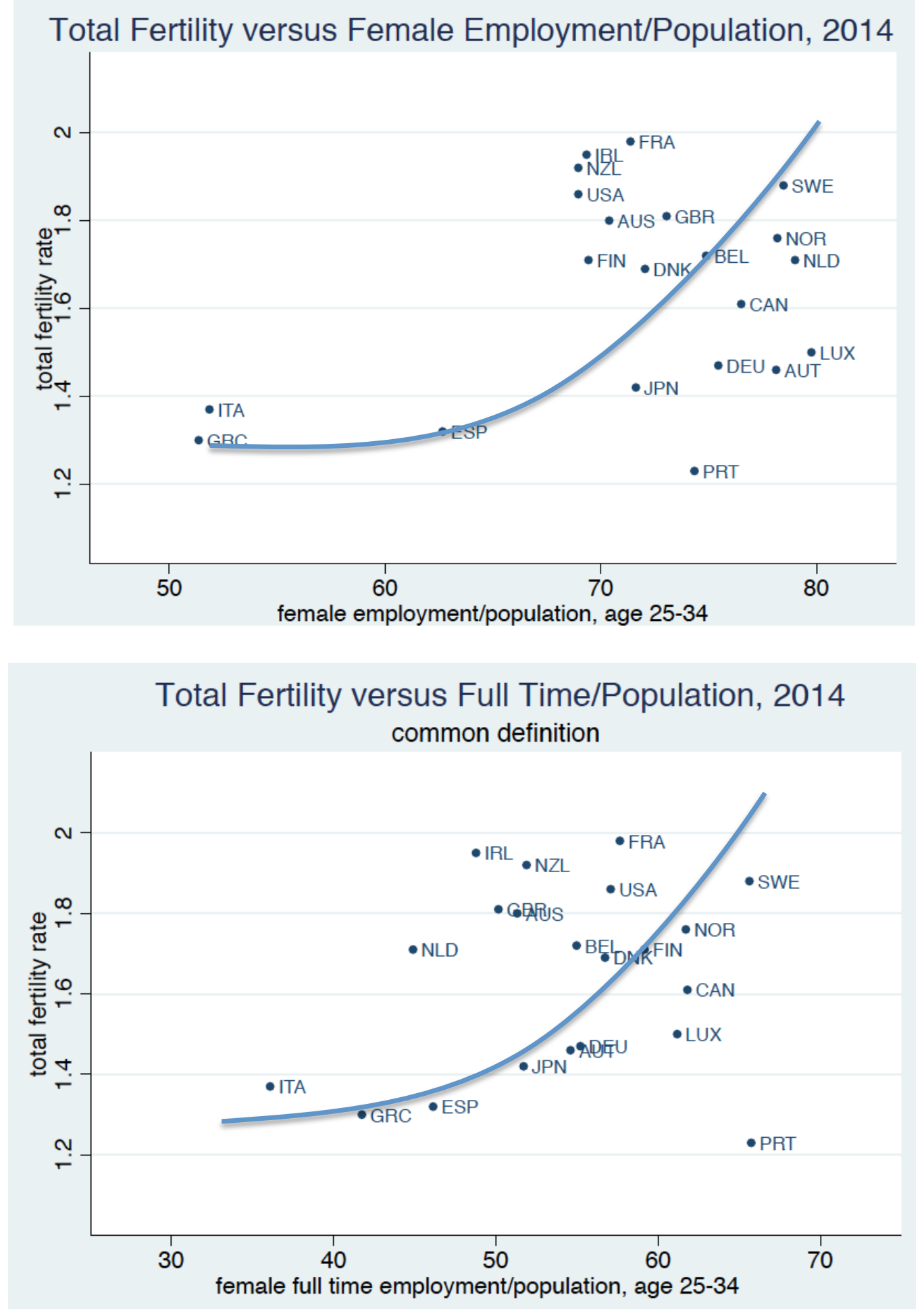

Sources: OECD https://stats.oecd.org. The "common definition" of full-time (30 hours/week and above at employee's usual job) is used rather than the national definition of full-time employment. 
Figure 5: Female Labor Force Participation, Seven OECD Nations, 1990-2014: 60-64 and 65-69 years

\section{Part A: 60 to 64 Years Old}

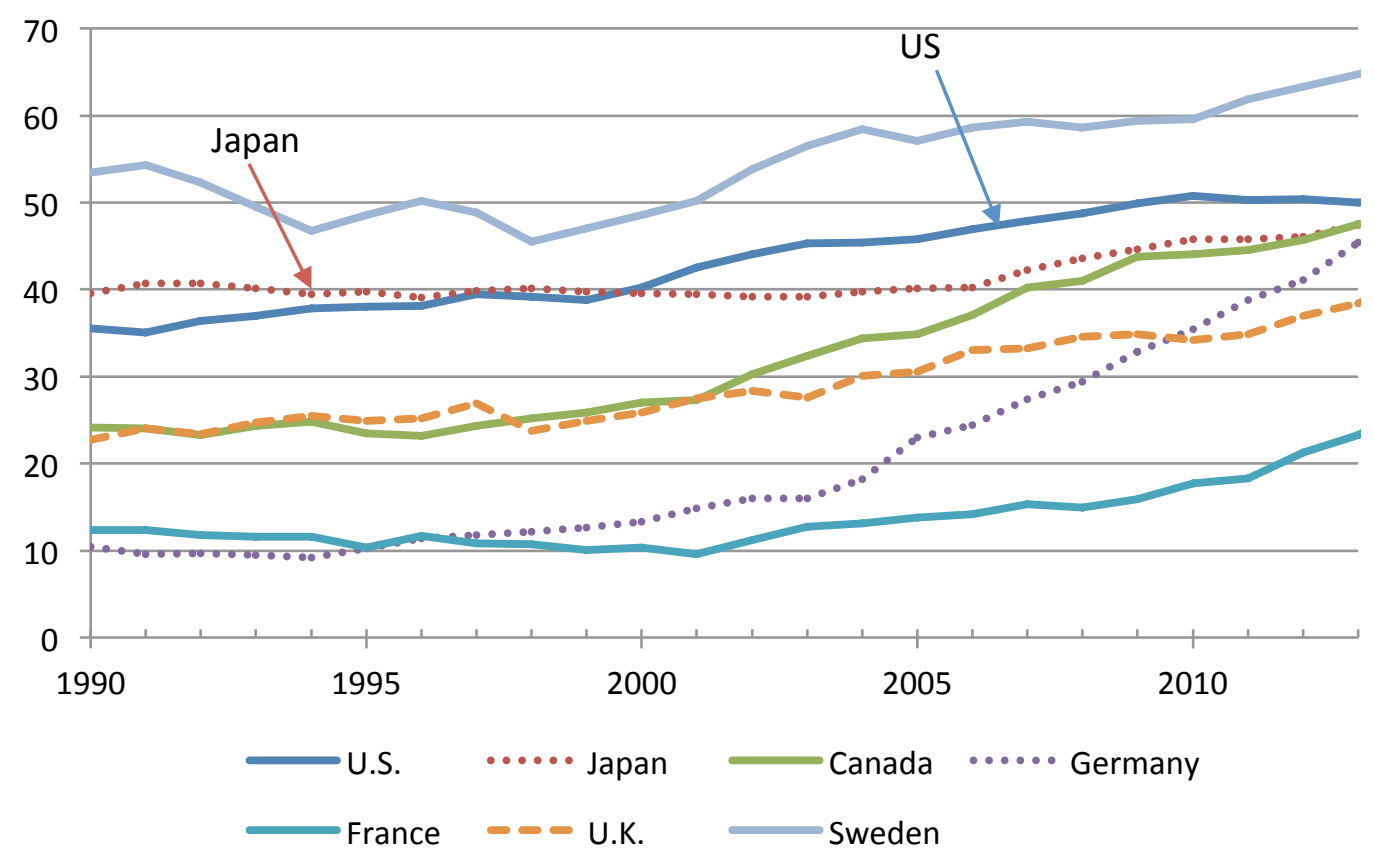

Part B: 65 to 69 Years Old

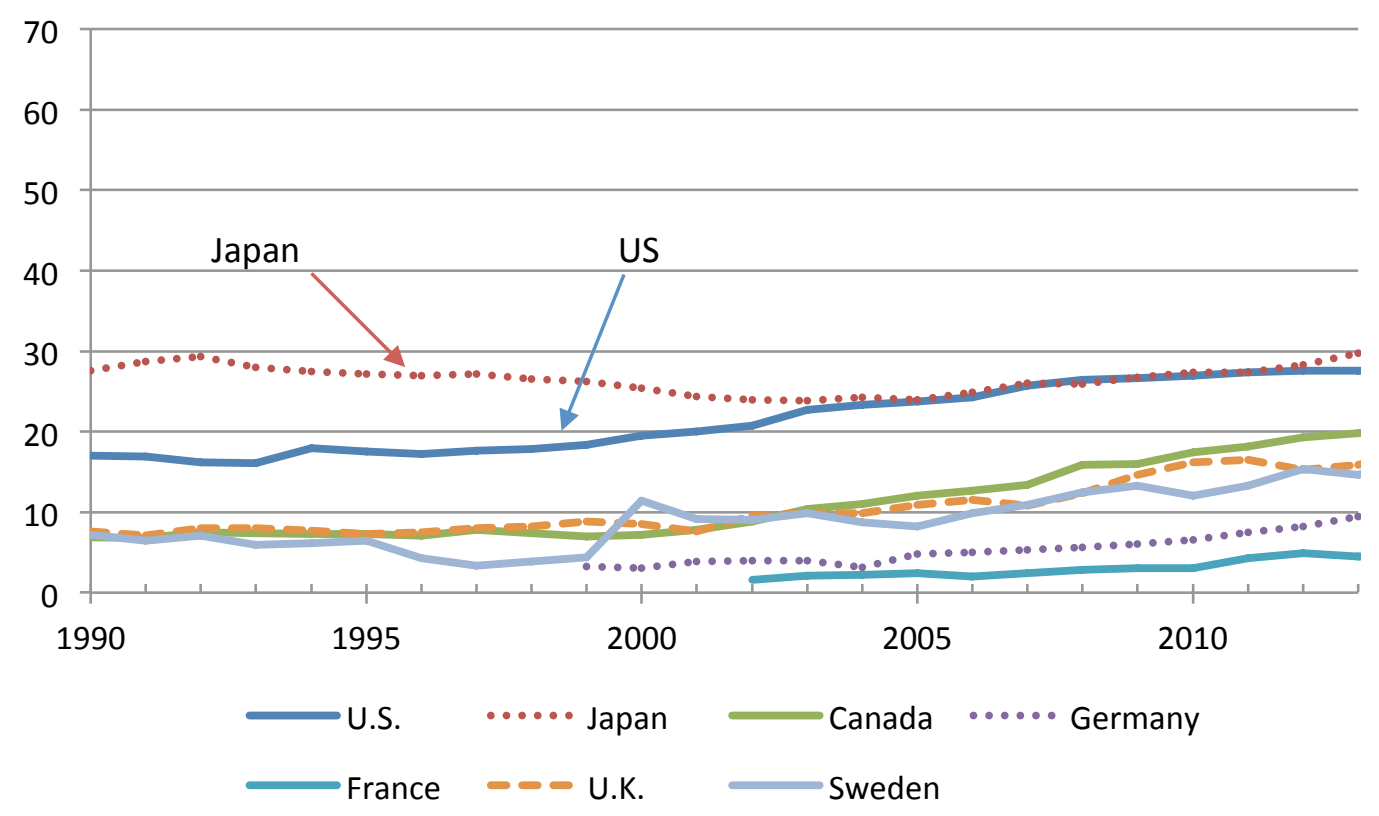

Source: OECD, https://stats.oecd.org; data for 65 to 69 year olds in Japan after 2001 provided by ESRI. 
Figure 6: Female Labor Force Participation by Five-Year Age Groups, 1962 to 2014

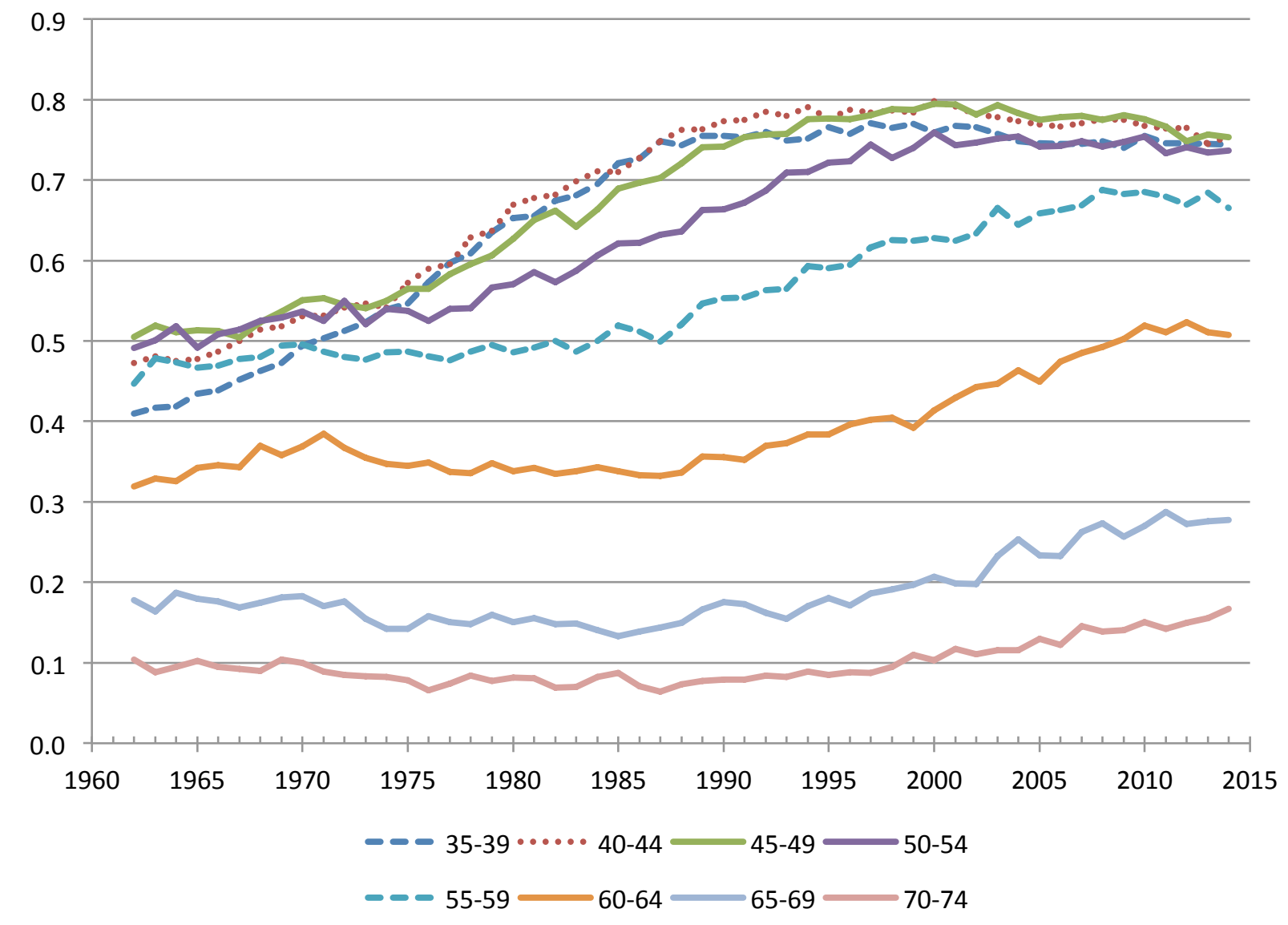

Source: March CPS, micro-data. 
Table 1: Total Fertility Rate in Japan: 1925 to 2014

\begin{tabular}{cc}
\hline Year & $\begin{array}{c}\text { Total Fertility Rate } \\
\text { in Japan }\end{array}$ \\
\hline 1925 & 5.099 \\
1930 & 4.705 \\
1940 & 4.114 \\
1947 & 4.543 \\
1950 & 3.651 \\
1955 & 2.370 \\
1960 & 2.004 \\
1965 & 2.139 \\
1970 & 2.135 \\
1975 & 1.909 \\
1980 & 1.746 \\
1985 & 1.764 \\
1990 & 1.543 \\
1995 & 1.422 \\
2000 & 1.359 \\
2005 & 1.260 \\
2010 & 1.387 \\
2014 & 1.422 \\
\hline \hline
\end{tabular}

Source: Japanese National Institute of Population and Social Security Research, Latest Demographic Statistics. 
Table 2: US Labor Force Participation Rates for Males and Females, 55 to 74 Years: CPS

\begin{tabular}{|c|c|c|c|c|}
\hline \multirow[t]{2}{*}{ Age Group } & \multirow[t]{2}{*}{ Educational Group } & \multicolumn{2}{|c|}{$\begin{array}{l}\text { Labor Force Participation } \\
\text { Rate in }\end{array}$} & \multirow[t]{2}{*}{$\begin{array}{l}\text { Percentage Point Change } \\
\text { c.1988 to c. } 2013\end{array}$} \\
\hline & & 1987-89 & $2012-14$ & \\
\hline \multicolumn{5}{|l|}{ Women } \\
\hline \multirow[t]{3}{*}{$55-59$} & All & 0.522 & 0.673 & 15.1 \\
\hline & College graduates & 0.685 & 0.779 & 9.4 \\
\hline & Non-college grad. & 0.499 & 0.627 & 12.8 \\
\hline \multirow[t]{3}{*}{$60-64$} & All & 0.341 & 0.514 & 17.3 \\
\hline & College graduates & 0.454 & 0.612 & 15.8 \\
\hline & Non-college grad. & 0.330 & 0.472 & 14.3 \\
\hline \multirow[t]{3}{*}{$65-69$} & All & 0.153 & 0.276 & 12.3 \\
\hline & College graduates & 0.240 & 0.367 & 12.7 \\
\hline & Non-college grad. & 0.145 & 0.244 & 9.9 \\
\hline \multirow[t]{3}{*}{$70-74$} & All & 0.072 & 0.157 & 8.6 \\
\hline & College graduates & 0.130 & 0.214 & 8.3 \\
\hline & Non-college grad. & 0.066 & 0.142 & 7.5 \\
\hline \multicolumn{5}{|l|}{ Men } \\
\hline \multirow[t]{3}{*}{$55-59$} & All & 0.796 & 0.779 & -1.8 \\
\hline & College graduates & 0.886 & 0.896 & 1.0 \\
\hline & Non-college grad. & 0.773 & 0.728 & -4.6 \\
\hline \multirow[t]{3}{*}{$60-64$} & All & 0.548 & 0.607 & 5.9 \\
\hline & College graduates & 0.682 & 0.727 & 4.5 \\
\hline & Non-college grad. & 0.516 & 0.543 & 2.8 \\
\hline \multirow[t]{3}{*}{$65-69$} & All & 0.258 & 0.380 & 12.2 \\
\hline & College graduates & 0.402 & 0.491 & 8.9 \\
\hline & Non-college grad. & 0.231 & 0.321 & 9.0 \\
\hline \multirow[t]{3}{*}{$70-74$} & All & 0.155 & 0.232 & 7.7 \\
\hline & College graduates & 0.254 & 0.324 & 7.0 \\
\hline & Non-college grad. & 0.141 & 0.191 & 5.0 \\
\hline
\end{tabular}

Source: March CPS micro-data. 